\title{
Allogeneic GM-CSF-secreting Tumor Vaccine PANC 10.05 pcDNA-1/GM-Neo
}

National Cancer Institute

\section{Source}

National Cancer Institute. Allogeneic GM-CSF-secreting Tumor Vaccine PANC 10.05

pCDNA-1/GM-Neo. NCI Thesaurus. Code C101892.

An allog eneic cancer vaccine composed of lethally irradiated, whole pancreatic cancer cells transfected with a plasmid carrying the gene for cytokine granulocyte-macrophage colony-stimulating factor (GM-CSF), with potential immunostimulating and antineoplastic activities. Allog eneic GM-CSF-secreting tumor vaccine PANC 10.05 pcDNA-1/GM-Neo secretes GM-CSF thereby activating dendritic cells, promoting antigen presentation to Band T-cells, and promoting a cytotoxic T-lymphocyte (CTL) response. This may eventually kill tumor cells. The pancreatic tumor cells are derived from the PANC 10.05 tumor cell line. 